\title{
Discussion on the Influence of Network Sports Information on College Students' Sports Consciousness and Behavior
}

\author{
Chao Ye $\mathrm{e}^{1, \mathrm{a}}$ \\ ${ }^{1}$ Polytechnic institute of Jiangxi Science and Technology Normal University, Nanchang, Jiangxi, \\ 330100
}

Keywords: Network Information; College Students; Sports Awareness and Behavior; Influence

\begin{abstract}
With the rapid development of network information technology, the dissemination of network information is no longer time and space constraints, network sports information is also rapidly into the people's attention. The application of network information technology not only promoted the reform process of traditional teaching mode, but also had an important influence on the sports consciousness and behavior of college students. This paper discusses the positive and negative effects of the development and dissemination of network sports information on college students' sports consciousness and behavior, and puts forward some suggestions.
\end{abstract}

\section{Introduction}

Network platform information has the following characteristics: huge, open, interactive, timeliness. Network information technology platform for the release of various types of sports information, circulation, not only ease the pressure of students to learn, relax the mood of students, but also on college students' sports awareness and sports behavior has an important impact on the role. Colleges and universities should make full use of these platforms to promote the development of school physical education, to help students establish the correct concept of sports, cultivate the correct sports spirit, and then change the student's sports behavior.

\section{The Status Quo of College Students Sports Activities}

For college students, they have plenty of extracurricular time to dictate. Some students will use extracurricular time to the library to broaden their knowledge, some students will go out with their partners to play, and some students will go to the gym or gymnasium exercise, and students are accustomed to stay in their own quarters do not go out. From the extracurricular time distribution of students, we can find that most of the students have very few sports activities, almost no conscious exercise, for sports show an optional attitude. Only a small number of students correctly recognized the importance of physical exercise, realized that sports activities can not only enrich their own after school life, but also to achieve the effect of Johnson \& Johnson fitness. Part of the reason is that the university life is loose, the lack of school sports organizations, greatly increased the student's inertia, so vicious circle, students naturally participate in sports awareness is very weak.

At present, many colleges and universities do not have a full range of sports equipment, there is no formal sports space, coupled with sports is also limited by the constraints of the environment, which students participate in sports activities have a certain impact. There is also a reason is that schools do not attach importance to the education of sports and cultural knowledge, and did not improve the relevant knowledge education classroom, the publicity of sports activities, nor the introduction of formal offices and work processes, which did not mobilize the enthusiasm of the student movement. However, the emergence of network information technology for the development of college physical education and the establishment of student sports awareness has brought a strong platform, schools should follow the pace of the times to make good use of network information technology, make rules of the relevant regulations, improve sports education System to help students form a healthy sports awareness and sports behavior. 
Highly developed network information platform has a huge, timeliness and other characteristics, it is the network information platform of these features so that students can not only understand the network platform for more sports information, you can also be interested in the information to share to friends circle or Share to your friends. Each student's motivation to contact the network sports information is always different, mostly different. Such as: to understand their favorite sports stars, to understand the recent sports competition, improve their level of sports knowledge. Through the contact of the network of sports information, students can understand many of the classroom can not learn sports knowledge, face all kinds of sports events, whether positive or negative information can be the first time to contact, and express their own understanding. Correctly deal with the network of sports information, for students to establish the correct sense of sports, to improve their enthusiasm for participation in sports activities, has a great help.

\section{The Positive Impact of Online Sports Information}

Consciousness refers to the influence of a certain thing, through long-term understanding and practice formed by the idea [1]. Sports awareness is one of the important components of college students' sports. Can we establish the correct sports consciousness to determine the sports behavior of college students. The establishment of sports awareness is a long process, and can not see results. Therefore, the rapid development of network information technology has an important influence on the formation of college sports consciousness. Through the form of the network, college students can learn more about sports information, and can choose their own interested in sports information. For the students living in the era of rapid development of information technology, the network media technology has the permeability is inevitable, the network sports information virtually affect the formation of student sports awareness.

Today, the APP in the phone has a variety of sports news information, especially when the major sports competitions, such as this year's Rio Olympic Games. QQ, WeChat Tencent news and microblogging Sina microblogging, according to the process of the game continue to push the news about the results of the game, and sometimes push the funny content of sports news, attracting no college students to watch the news eye The College students in the process of watching positive news is to understand the process of sports knowledge, and unknowingly set up their own sports awareness.

Sports behavior refers to the activities in order to meet a certain sports needs, is the formation of human sports awareness under the leading role. The emergence and development of network sports information is of great significance to the formation of college students' sports behavior. Under the influence of network sports information, college students understand more and more sports knowledge, sports behavior also will continue to change. For example, many students understand which time to run the most beneficial to good health and they will subconsciously make good use of this time to the school playground to run. Learned that long-term adherence to running can not only relax, but also can achieve the effect of shaping the body, running will naturally become a lot of female students sports behavior.

Many students make it to publish their own sports behavior, and use software for their own sports behavior to develop a complete plan. You can also according to their own sports behavior needs to select the appropriate project, you can also tailor-made for your plan. In addition to APP, micro-blogging and QQ which have pedometer, record the number of steps walking every day, and automatically in the friends in the public ranking. Micro-blogging and QQ pedometer appears to attract a lot of students to use, began to pay attention to their own health, and then changed their own sports behavior.

\section{The Negative Impact and Recommendations}

Network sports information Chung Chung, so that students can obtain a wealth of sports information at the same time there is a certain negative impact. For the mass of sports information, students do not have a good ability to judge, can not tell the true and false news information. The 
current phenomenon of cheating in sports competitions also spread through the network platform to the network sports information, such as sports violence news, athletes bribe the referee news, an athlete taking doping news [2]. These negative sports news will not only affect students 'understanding of sports culture in our country, but also have a huge negative effect on students' correct understanding of sports, and it is easy to mislead students to establish the wrong sports values. With the internationalization of sports culture, some of the domestic sports rules used in the international community will not be supported, so the loss of sports reports, affecting students' confidence in the development of sports in China, instead of other countries, sports blind Of the worship, is not conducive to the development of China's international sports culture.

Therefore, the face of massive online sports information, students should improve their own ability to judge the true and false, consciously resist the negative impact of online sports information. Colleges and universities should strengthen the importance of sports, increase investment in physical education, improve the sports equipment. In the student dormitory to install free TV, arrange students to watch sports games and sports news weekly, and write a few hundred words after a sense of view. Students can watch the latest sports information, enrich their own sports knowledge, and slow down their learning pressure by watching sports and news.

Take the combination of network physical education and traditional physical education teaching methods to improve students' participation in physical education activities, so as to improve the efficiency of students learning sports knowledge. The establishment of school network sports information supervision agencies, to provide students with a healthy learning environment. To carry out various forms of physical education activities, such as sports knowledge lectures, students use the network information platform to be the correct guide. Add a network of information sports courses to improve students' ability to distinguish news and information. In order to reduce the negative impact of online sports information, the school can also take the initiative to establish interaction with the network platform, targeted cooperative relations, increase the positive impact of network sports information on students. Only in the joint efforts of students and teachers, in order to make full use of network information technology to change the current situation of college students' sports activities.

\section{Conclusion}

To sum up, the network technology is one of the important channels for college students to understand sports information and obtain sports knowledge. Network sports information can help students to establish the correct sports awareness, improve students' sports behavior, enrich students' spare time, improve students' physical quality. Of course, network information technology has advantages and disadvantages. Network platform to provide students with a wealth of sports information at the same time will give students a certain negative impact, students need to enhance their ability to judge, get the right sports information, consciously resist bad sports information.

\section{References}

[1] Chen Jianhong. Network information technology on the impact of sports culture in colleges and universities [J]. Enterprise Herald, 2013, 24: 176-177

[2] Xuan Daling. Mass media sports information on the impact of college students [J]. News front, 2015, 03: 157-158 